\title{
Materialism and Its Effect on Psychiatric Morbidity of Indian
}

\section{Students}

\author{
Ankita Biswas $^{1 *}$, Sanjukta Das ${ }^{2}$
}

\section{ABSTRACT}

The emergence of globalization and consumerism in the modern world has led to an inevitable consequence in the form of materialism which has an undeniable influence on psychological well-being. The purpose of the present study is to investigate the influence of materialism on psychiatric morbidity, with respect to state and trait anxiety, depression and global psychiatric morbidity. Using a cross-sectional design, data were collected following purposive technique from 200 undergraduate and postgraduate students categorized with respect to grade and sex. Analysis of data was done employing descriptive statistics and three-factor factorial analysis of variance. The results revealed significant effects of grade, materialistic value, intrinsic aspiration and hedonistic aspiration on the different aspects of psychiatric morbidity. However, no such effect was found for sex, extrinsic aspiration and spiritual aspiration. The findings may contribute to the understanding of the role of a materialistic culture in the mental health of Indian students.

Keywords: Materialistic Value, Aspiration Goals, Psychiatric Morbidity, Depression, Anxiety

With the advancement and rapid changes in education, technology and socio-political scenario, and the advent of industrialization, globalization and consumerism in the present day world along with its innumerable contributions in pacing up the advancement of society has brought along certain aspects as inevitable consequences which is leading to a steady deterioration in mental health in millions across the globe. One such emerging phenomenon is materialism which has come into prominence and recent research attention for its undeniably overwhelming influence on psychological well-being. The modern world has witnessed a shift towards a consumerist culture where material consumption is equated with happiness and this trend is most markedly observed among the young generations. The present study thus endeavors to throw light on this emerging area of concern that has been less explored in Indian culture, and to explore its role in causing psychiatric morbidity in the youth. Psychiatric morbidity generally refers to the incidence of both physical and

\footnotetext{
${ }^{1}$ Clinical Psychologist \& Teaching faculty at Institute of Psychiatry, Centre of Excellence, IPGMER-SSKM Hospital, Kolkata, West Bengal, India

${ }^{2}$ Associate Professor \& current Head of the Department, Department of Psychology, University of Calcutta, Kolkata, West Bengal, India

*Responding Author

(C) 2017 Biswas A \& Das S; licensee IJIP. This is an Open Access Research distributed under the terms of the Creative Commons Attribution License (www.creativecommons.org/licenses/by/2.0), which permits unrestricted use, distribution, and reproduction in any Medium, provided the original work is properly cited.
} 
psychological deterioration as a result of a mental or psychological condition. Arrays of various factors that originate from the interactions among the various components of present day lifestyle are contributory to development of this undesirable mental condition. In this study, 'materialism', defined as the tendencies towards materialistic pursuits, to desire and acquire material objects not strictly needed for subsistence and to view happiness and success in terms of what one owns (Henry, 2006) has been studied from two broad perspectives: the value perspective and the goal or aspiration perspective. Materialistic value refers to the extent to which a person considers material possessions as important, valuable and indispensable. Aspirations refer to people's life goals. A growing body of research shows that many goals can be arranged on a continuum from intrinsic to extrinsic. Goals such as self-acceptance, affiliation, and community feeling have been classified as "Intrinsic," for their focus on pursuits that are inherently rewarding and that tend to satisfy innate psychological needs such as autonomy, competence, and relatedness (Deci and Ryan, 2000). At the other end of the continuum, Extrinsic aspiration have their focus on external rewards, praise, and attaining possessions and includes goals such as financial success, attractive appearance, and social popularity (Kasser and Ryan,1996). Hedonism or Hedonistic aspiration denotes the motivation and aspiration towards pursuits of activities that leads to “experience much sensual pleasure”, (Grouzet et al. 2005). Spiritual aspiration refers to aspiring "to the search for spiritual or religious understanding" and activities in life for the attainment of meaning and well-being in life. According to the conceptualization and scale of Aspiration Index as constructed by Kasser \& Ryan, 1993, it is was found that neither spirituality nor hedonism goals could be classified as typically intrinsic or extrinsic, because they do not consistently conform to the conceptual criteria of satisfying inherent psychological needs (i.e., for intrinsic goals) or of involving the pursuit of external rewards or praise (i.e., extrinsic goals). As such, spirituality and hedonism might form the basis of the proposed orthogonal dimension of self-transcendent versus physical goals. These aspiration goals were represented in the form of a circumplex model proposed by Grouzet et al. 2005(Fig.1).

Research shows that extrinsic aspects such as material wealth are much poor at satisfying people's needs and paradoxically undermine psychological health and well-being. Fulfilling psychological needs are necessary for survival, growth and optimal functioning. When these needs are met people flourish and are at peace but when they are not they feel dissatisfied, unfulfilled and at worst mentally ill. Various past researches documented materialistic value to be inversely related to happiness and well-being in students and to be positively correlated with an array of specific negative health factors that include physical symptoms of illness (Kasser \& Ryan, 1996). They have shown that high materialistic value correlates significantly with high levels anxiety and depression (Watchel \& Blatt, 1990; Kasser \& Ryan, 1993) and with higher occurrences of a variety of mood, conduct, substance abuse and personality disorders (Cohen \& Cohen, 1996). The studies reported so far on aspiration goals have mostly explored the dimensions of intrinsic and extrinsic aspiration. Studies on college students who were focused on intrinsic goals were found to have high well-being whereas the 
reverse was true for a focus on extrinsic goals (Schmuck, Kasser, Ryan, 2000). In other words, materialistic pursuits do not contribute to a flourishing life.

The present study thus aims to examine the significance of these factors along with curricular grade and sex in psychiatric morbidity in undergraduate and postgraduate students. Henceforth, in the present paper, the undergraduate and postgraduate curricular levels will be referred to as 'grade'. Psychiatric morbidity generally refers to the incidence and prevalence of both physical and psychological deterioration as a result of a mental or psychological condition. In the present study, four dimensions based on four corresponding psychiatric components have been used. These components are stated as Trait Anxiety, State Anxiety, Depression and Global Psychiatric Morbidity. Established and standardized tools provide measures on the basis of which the resulting dimensions have been operationally defined. For the present study these dimensions correspond to the types of psychiatric morbidity. For the purpose of the present study, Global psychiatric morbidity which assessed by the general health questionnaire (GHQ) can be operationally defined as the overall psychiatric morbidity of an individual resulting from both physical and psychological deterioration and distress.

\section{Need and Significance/Scope of the Study:}

The study area on which the present investigation has been conducted has its importance because the study groups consisted of undergraduate and postgraduate students. These students are pursuing their education and in future they will be entrusted with the building of nation. All the societies take special care about this sector of the population and they are mostly concerned with their health in general and mental health in particular. The purpose of the present study is to examine the status of mental health and investigate the prevalence of psychiatric conditions within this specific social category. The study aims to investigate the influence of certain variables on psychiatric morbidity among the young adults of both sexes. The variables selected for the study include materialism and aspiration goals which are being perceived by the young generation of the Indian society as an emerging issue and these factors are found to influence their personality and mental health in their relevant life situations. Most of these variables have not been explored adequately and their impact on mental health is not clearly been reported in the context of the Indian culture. The present study aims to investigate psychiatric morbidity as affected by these variables. The outcomes of the study are expected to provide some indications on the basis of which mental health programs for the young generation, particularly the student community, may be organized.

\section{Aims \& Objectives:}

The aim of the present study is to investigate psychiatric morbidity among undergraduate and postgraduate students belonging to both sexes as affected by Materialistic value and Aspiration goals. The objectives of the study are stated as follows:

1. To determine the main effects of grade, sex and materialistic value along with their interaction effects on each of the types of psychiatric morbidity, namely, Trait anxiety, State anxiety, Depression, and global psychiatric morbidity. 
2. To determine the main effects of each of intrinsic, extrinsic, hedonistic and spiritual aspiration goals along with their interaction effects of grade and sex on each of the types of psychiatric morbidity as stated in objective 1 for each group of students.

\section{METHODOLOGY}

\section{Sample}

The sample for the present study comprised of 200 students selected from Undergraduate colleges and University Postgraduate departments with co-educational setup, using a purposive sampling technique. There were 100 undergraduate and 100 were postgraduate students with a mean age of 19.5 years and 23 years respectively. The numbers of male and female students, irrespective of grade were 105 and 95 respectively. The total sample was classified on the basis of grade and sex into 4 groups. In which the undergraduate group consisted of 55 males and 45 females, while for the postgraduate group there were 50 students in each sex.

The students were selected on the basis of the following inclusion and exclusion criteria:

\section{Inclusion Criteria:}

1. Age between 18 to 21 for undergraduate and 22-25 for postgraduate students.

2. Students presently pursuing their curricular studies in undergraduate or postgraduate course in any discipline.

3. Students belonging to urban families.

4. Students willing to participate in the study.

\section{Exclusion Criteria:}

1. Any kind of physical or mental disability.

2. Past history of psychiatric illness in the family.

3. Students with history of any severe illness.

4. Married, divorced or widowed.

5. Working in a registered organization before or after college hours.

In order to assess the degree of homogeneity of the groups of students, they were matched using the statistical technique of chi-square. The undergraduate and postgraduate students were matched with respect to sex and also these groups were further matched on the basis of family type, size of sib ship and birth rank.

\section{Instruments}

1. Information Schedule: The schedule was prepared to collect relevant personal and familial information about the participants.

2. Richins And Dawson Material Value Scale (Short form,1992): The Material Value Scale (MVS) was developed to measure materialistic values in individuals. Richins and Dawson define materialism as the importance ascribed to the ownership and acquisition of material goods in achieving major life goals or desired states. 
3. Aspiration Index: The Aspiration Index (AI) is a way of assessment of various goals within an individual's personal goal system. The original version of the AI was published by Kasser and Ryan (1993). The scale used in the present study is a later version of the AI (Grouzet, Kasser and others, 2005) which measures intrinsic, extrinsic, hedonistic and spiritual aspirations or goals.

4. General Health Questionnaire (GHQ): Developed by Goldberg and Miller (1979), GHQ was designed to be a self administered questionnaire that is used as a screening tool to detect those likely to have or be at risk of developing psychiatric disorders in the general population. The GHQ-28 version is used here which consists of 4 subscales for Somatic symptoms, Anxiety and insomnia, Social dysfunction and Severe depression.

5. Beck Depression Inventory (BDI): This inventory, developed by Beck et al. (1961), is used in the present study to measure the subjective level of depression.

6. State Trait Anxiety Inventory (STAI): Designed by Spielberger et al. (1970), STAI is used here to assess anxiety in two distinct forms, viz., State anxiety and Trait anxiety.

\section{Procedure}

After meeting the initial formalities of permission and assured cooperation from the concerned authorities the data were collected from the participants. Written consent was taken from them. The test materials following the standard procedures were administered on participants in groups, with each group consisting of 10 to 12 participants. The orders of presentation of tests were varied for different groups to avoid order effect, though the Information Schedule was presented at first in all the groups. On the basis of the information obtained from the information schedule, those participants were selected who fulfilled the inclusion and matching criteria and they constituted the sample of the present study. In this way, data were collected from about 230 participants among whom 200 participants were selected for the present study. Each datum was scored according to the standard scoring method as stated in the respective test manual.

\section{RESULTS}

The data obtained from the different groups of participants were expressed as the measures of the variables and these obtained measures constituted statistical distributions for the different groups. The data as represented in different distributions were then analyzed statistically in line with the objectives of the study as stated earlier. Analysis of data was done using SPSS software version 20. At first, the descriptive statistics in terms of means and standard deviations of the distributions of each of the types of psychiatric morbidity with respect to levels of grade and sex were computed (Tables 1 and 2).

The next phase of analysis was done by taking into consideration the distributions of high and low values in materialistic scale and each of aspiration goals for the different groups classified on the basis of grade and sex. For the purpose of the analysis, each of the distributions of a grade-sex group was split along the median and according to this median split the participants were categorized into the two sub-groups- high and low. The means and 


\section{Materialism and Its Effect on Psychiatric Morbidity of Indian Students}

standard deviations of each of these distributions were computed for the different variables in each of the types of psychiatric morbidity (Tables 3-7)

An attempt was made in the next phase of analysis to use the inferential statistical technique of factorial analysis of variance (Kerlinger, 1985). A three factor factorial analysis of variance was used for testing the significance of main effects of each of the factors and also the significance of interactions between two and among three factors for the measures of each of the types of psychiatric morbidity (Tables 8-12). Prior to the factorial analysis of variance, Levenes's test of equality of variance was used to test the homogeneity of variance of the distributions. According to the results of Levene's test homogeneity could be assumed in each case using ANOVA.

The results obtained from the three factor factorial ANOVA revealed that the main effect of materialistic value (MV) as a factor is highly significant in all the types of psychiatric morbidity, namely, state anxiety (SA), trait anxiety (TA), depression (Dep) and global psychiatric morbidity (GPM) (see table 8). This indicates that the difference between the means of high and low MV averaged over the level of grade and sex is highly significant (SA: F=12.298; $\mathrm{df}=1,192 ; \mathrm{p}<0.001$, TA: $\mathrm{F}=12.480$;f $=1,192 ; \mathrm{p}<0.001$, Dep: $\mathrm{F}=11.422$; $\mathrm{df}=$ $1,192 ; \mathrm{p}<0.001$, GPM: $\mathrm{F}=11.468 ; \mathrm{df}=1,192 ; \mathrm{p}<0.001)$. It was further shown that the means of high MV group are significantly greater than those of low MV group in all the types of psychiatric morbidity (Table 3). Both the two factor and three factor interaction effects were not found to be significant which revealed that the main effects of MV was independent of the influence of grade and sex for its effect on psychiatric morbidity. The obtained result also showed that the main effect for grade was found to be significant in respect of Dep ( $F=4.575$; $\mathrm{df}=1,192 ; \mathrm{p}<0.005)$ and $\mathrm{GPM}(\mathrm{F}=6.835 ; \mathrm{df}=1,192 ; \mathrm{p}<0.005)$. It might be interpreted similarly that the difference between the means of undergraduate (UG) and postgraduate (PG) levels averaged over the levels of sex and MV is significant and the effect of grade did not depend on sex and MV since none of the interaction effects was found to be significant. The results further indicated that the means of UG group are significantly greater than those of PG group in case of both Dep and GPM (Table 1). The results of the present factorial ANOVA, however, revealed that the main effect for sex was not significant in any of the types of psychiatric morbidity.

The three factor ANOVA when included Intrinsic Aspiration (IA) as a factor, the results showed a significant main effect for the IA only in trait anxiety (Table 9). This reveals that the mean of low IA is significantly greater than that of high IA (Table 4). This significant main effect was also found to be independent of the influence of grade and sex.

Again, the analysis of data demonstrated that the main effect of hedonistic aspiration (HA) was significant for psychiatric morbidity of Dep and GPM (Table 11). The obtained findings also revealed that the means of high HA group was significantly lower than the means of low HA group for Dep and GPM (Table 6). Here also the main effects of HA are independent of the influence of grade and sex since the interaction effects were not significant. 
The three factor factorial AVOVA revealed that the main effects for sex, extrinsic aspiration (EA) and spiritual aspiration (SpA) were not found to be significant in any of the types of psychiatric morbidity. The results of factorial ANOVA also provided significant interaction effects, both two-factor and three-factor, for each of the types psychiatric morbidity,

It may be stated here that the results obtained from the analysis of data appear to have examined and fulfilled the objectives of the study.

\section{DISCUSSION}

The present study is concerned with the influence of certain variables on psychiatric morbidity among students pursuing curricular studies at undergraduate (UG) and postgraduate (PG) levels. The results obtained from the statistical analysis of data have revealed certain interesting trends in the findings with regard to psychiatric morbidity and characteristics of the students participated in the study as subjects.

Psychiatric morbidity as affected by certain variables has been investigated in the present study. Among the variables, materialistic value (MV) needs to be mentioned first since this is the variable which exerts a highly significant influence on the different types of psychiatric morbidity. The present findings are found to be in line with Kasser \& Kanner (2004) who in one of their studies reported that materialism appears to be one of the most significant causes of lack of fulfillment and well-being in life. In earlier studies, Sirgy (1998) also reported findings in the same line that materialism is associated with lower levels of life satisfaction, fulfillment and emotional well-being. The findings of the present study conducted on UG and PG students have also been supported by Christopher et al. (2004) who in a study on 159 US college students found that materialism is related to lower levels if psychological well-being and inversely related to positive affect. The findings of the present study which show significant differences between high and low MV on psychiatric morbidity have also been supported by findings of Belk (1984) which demonstrate a negative correlation between materialism and aspects of emotional well-being.

The findings with regard to depression as influenced by MV have also been supported by a longitudinal and cross sectional study conducted by Smith (2010) on the relationship between materialism and depressive symptoms. It might be stated here that many studies have examined the relationship between materialism and aspects of emotional well-being while a handful of studies looked specifically at the relationship between MV and depression. Some other study reports have provided support to the relationship between materialism and depression, among which a study conducted by Cohen \& Cohen (1996) revealed that higher levels of MV were found to be correlated with higher occurrences of a variety of mood, conduct, substance abuse, and personality disorders.

The findings have also indicated a definite bearing of MV on anxiety- both state and trait anxiety. These findings are found to be corroborated with those reported by Watchel \& Blatt (1990), and Kasser \& Ryan (1993) in which they reported connections between high levels of

(C) The International Journal of Indian Psychology, ISSN 2348-5396 (e)| ISSN: 2349-3429 (p) | 120 
materialism in individuals and an array of negative health factors that include physical symptoms of illness and high levels of anxiety and depression.

The present study has shown a significant difference between UG and PG students in different forms of morbidity. The findings further show that the UG students are affected more than their PG counterparts. The mean age of UG students is close to 19 years 6 months and that of $\mathrm{PG}_{=}$students to 23 years. This age-wise divisions of the two grade groups indicate that most of the UG students belong to the stage of post- adolescence while PG students to young adulthood. The vulnerability of UG students compared to the PG group may be explained in line with the findings reported by Reinherz et al. (1999) in which they stated that generally the transition to adulthood represents a period with high risk for the onset of psychiatric morbidity, especially depression. K.N. Rao \& Shamshad Begum (1994) concluded in their study that college students represented $5.1 \%$ of the clinic population compared to illiterate youths who represent a 3.1\%, in India. It is estimated that about $10 \%$ to $30 \%$ of university students have emotional problems leading to psychological distress (Ramani \& Sathyavathi, 1971; Farnsworth, 1975; Chandrashekhar et al. 1980; Thacore \& Gupte, 1972).

The present findings have provided a non-significant difference so far as sex is concerned with regard to its influence in psychiatric morbidity. The influence of sex with respect to its interaction with materialistic value has also not been found to be different for male and female subjects. The finding of non-significant sex difference as provided by the present study has its support in the findings of many other studies on psychiatric morbidity. In the study by Jenkins in 1985, no sex difference in prevalence of minor psychiatric morbidity, nor in its outcome was found in a population of men and women of similar age, education, occupation, and social environment. However, women did report significantly more symptoms of psychogenic origin. Two different researches conducted by Bijl, Ravelli \& Zessen in 1998, and Grant et al in 2009, respectively concluded a similar finding that no gender difference exists in the development of psychopathology among the general population. Additional support for such a finding comes from a study by Tyssen et al. (2008), which reveals no gender difference in the development of psychiatric illness among postgraduate students.

The results obtained from the subjects with regard to different aspirations goals provide a mixed picture as to their impact on psychiatric morbidity. According to the obtained results intrinsic aspiration (IA) is found to have a bearing on mental health and it is found that this orientation to aspiration is inversely related to psychiatric morbidity, particularly with respect to trait anxiety. Since intrinsic orientation is claimed to be a factor enhancing self actualization, self-acceptance, belongingness and affiliation, and community feeling (Kasser \& Ryan, 1993), it protects the subjects from being victims of anxiety and ensures emotional stability. 
However, in the present study, the effect of extrinsic aspiration has not been found to be significant in any of the types of psychiatric morbidity.

The variables of hedonistic (HA) and spiritual aspirations (SpA), appear to be least explored and study reports in relation to their impact on psychiatric morbidity has not been clearly specified. The results of the present study, however, indicate significance of HA on Dep and GPM. In this area, a significant difference has been obtained between the subjects scoring high and low in HA on depression and GPM. Incidentally measures of HA and loading of depression and GPM is inversely related and as such the 'low' group of HA scores high on the scale of these two kinds of psychiatric morbidity. Interestingly, the UG male students are affected compared to UG female and PG students of both sex by HA affecting adversely their mental health.

The variable of SpA does not appear to show any significant bearing on any of the types of psychiatric morbidity investigated in the present study. The difference between the subjects in any of the grade-sex groups between high and low SpA is not significant. The nonsignificance of spirituality in the context of psychiatric morbidity might be due to the fact that student subjects, as in the present study, many a times fail to differentiate between religiosity and spirituality as these constructs overlap considerably.

The environmental and socio-political culture in which an individual is growing together with the present global scenario has huge influences in a person's mental make-up and many a times may come up as factors affecting mental health. With rapid changes in socio-cultural and political aspects, and the rise of industrialization and globalization, the present day world has also witnessed an ever increasing occurrence and prevalence of psychological ill-health and thus psychiatric morbidity has become a distressing reality and a major challenge across the world. An increased prevalence of psychiatric morbidity is also noticed among the young generations - the so called "future of a country", which is detrimental both for the individual and the world. Unfortunately, the picture is also the same in India.

With the rise of industrialization and consumerism, people are highly endorsed and encouraged to believe the idea that pursuit of wealth and material possessions provide a meaningful and happy life. As a result of internalizing such views, there is a rise of a consumer culture that has become more and more dominant, and the aspirations of materialism have been adopted and pursued by society at large. In developing marketing and advertising campaigns there is an open push for materialistic consumption. And the most affected victim of such societal transformation is the young people- the student community.

While individuals become more focused on their pursuits of material achievement and improving their standard of living, they simultaneously become depleted within their selves draining heavily on inner strength, intrinsic motivation, self actualization potential and satisfaction (Kasser \& Ahuvia, 2002) and self esteem (Richins \& Dawson,1992). This endeavor to search for happiness and meaning in life outside than within self also leads to 


\section{Materialism and Its Effect on Psychiatric Morbidity of Indian Students}

compromisations of spiritual resources and ethical values and in its extreme leads to the development of psychiatric morbidity.

\section{Acknowledgments}

The author appreciates all those who participated and assisted in the study to facilitate the research process.

Conflict of Interests: The authors declare that there are no potential conflicts of interest with respect to the research, authorship, and/or publication of this article.

\section{REFERENCES}

Beck, A.T. , Ward C.H. , Mendelson M, Mock J \& Erbaugh J. An inventory for measuring depression. Arch Gen Psychiatry, 1961, 4: 561- 71.

Belk, R. (1985), Materialism: Trait aspects of living in the material world. Journal of Consumer Research, 12, 265-280.

Belk, R. W. (1984). Three scales to measure constructs related to materialism: Reliability, validity, and relationships to measures of happiness. Advances in Consumer Research, 11, 291-297.

Bijl, R. V., van Zessen, G., Ravelli, A., de Rijk, C. \& Langendoen, Y. (1998). The Netherlands Mental Health Survey and Incidence Study (NEMESIS): objectives and design. Social Psychiatry and Psychiatric Epidemiology,33, 581 - 586.

Chandrashekar, C. R. ; Shamasundar, C. ; Kapur, R. L. ; Kaliaperumae, V. (1980) Mental morbidity among graduate and research students: an epidemiological study. Indian Journal of Psychiatry, 22 (1). pp. 89-93.

Christopher, A. N. \& Schlenker, B. R. (2004). Materialism and affect: The role of selfpresentational concerns. Journal of Social and Clinical Psychology, 23(2), 260-272.

Christopher, A. N., Kuo, V., Abraham, K. M., Noel, L. W. \& Linz, H. E. (2004). Materialism and affective well-being: The role of social support. Personality and Individual Differences, 37 (3), 463-470.

Cohen, P. \& Cohen, J. (1996). Life values and adolescent mental health. Mahwah, NJ: Erlbaum.

Ryan, R. M. \& Deci, E. L. (2000). Self-determination theory and the facilitation of intrinsic motivation, social development, and wellbeing. American Psychologist, 55, 68-78.

Farnsworth, D.L.(1975) College mental health services. In Comprehensive Textbook of Psychiatry. (Eds.A.M. Freedman, H.J.Kaplan \& B.J.Sadock) ,2nd Edition,Vol.11,pp 2270-2277 .Baltimore: Williams \& Wilkins.

Grant, B.F., Goldstein, R.B., Chou, S.P., Huang, B., Stinson, F.S., Dawson, D.A., Saha, T.D., Smith S.M., Pulay, A.J., Pickering, R.P., Ruan, W.J., Compton, W.M. (2009). Sociodemographic and psychopathologic predictors of first incidence of DSM-IV substance use, mood and anxiety disorders: results from the Wave2 National Epidemiologic Survey on Alcohol and Related Conditions. Molec. Psychiatr.; 14:1051- 1066. Pubmed. 
Grouzet, F., Kasser, T., Ahuvia, A., Dols, J., Kim, Y., Laus, S., et al. (2005). Goal contents across cultures: The structure of goal contents across 15 cultures. Journal of Personality and Social Psychology, Vol. 89. No. , 800-816.

Henry, C.D. (2006). Lowering the price(s) of materialism: can secure personal attachments be utilized to reduce materialistic values and behaviors? (Unpublished doctoral thesis) University of Georgia, Athens, Georgia.

Jenkins, R., Sex differences in minor psychiatric morbidity: A survey of homogenous population . J. Social Science \& Medicine Volume 20, Issue 9, 1985, Pages 887-899.

Kasser, T. \& Ahuvia, A. (2002). Materialistic values and well-being in business students. European Journal of Social Psychology, 32, 137-146.

Kasser, T. \& Kanner, D. (2004). Psychology and consumer culture: The struggle for a good life in a materialistic world. Washington, DC: American Psychological Association.

Kasser, T. \& Ryan, R. (1993). A dark side of the American dream: Correlates of financial success as a central life aspiration. Journal of Personality and Social Psychology, 65, 410-422.

Kasser, T. \& Ryan, R. M. (1996). Further examining the American dream: Differential correlates of intrinsic and extrinsic goals. Personality and Social Psychology Bulletin, 22, 280-287.

Kasser, T. (2002). Sketches for a self-determination theory of values. In E. L. Deci \& R. M. Ryan (Eds.), Handbook of self-determination research (pp. 123-140).Rochester, NY: University of Rochester Press.

Kasser, T., \& Kanner, A. D. (Eds.). (2004). Psychology and consumer culture: The struggle for a good life in a materialistic world. Washington, DC: American Psychological Association.

Khanna, S. \& Kasser, T. (2001). Materialism, objectification, and alienation from a crosscultural perspective. (unpublished manuscript)

Kerlinger, F.N.(1985). Foundations of Behavioural Research ( $3^{\text {rd }}$ edn).New York: Holt, Rinehart, and Winston. Lancet, 378(9793), 804-814.

Ramani, M.S. \& Sathyvathi (1971). Mental Health problems of college students -A pilot study. Transactions-II. All India Institute Of Mental Health pp29.

Rao, K.N. and Begum, B. Psychiatric morbidity in college students and illiterate youths. Indian J Psychiatry. 1994 Jul-Sep; 36(3): 141-144.

Ryan, R. M. \& Deci, E. L. (2000). Self-determination theory and the facilitation of intrinsic motivation, social development, and wellbeing. American Psychologist, 55, 68-78.

Reinherz, H.Z., Giaconia, R.M., Hauf,A.M., Wasserman, M.S., Silverman, A.B. (1999). Major depression in the transition to adulthood: risks and impairments. J. Abnormal Psychol., 108: 500-510.

Richins, M. \& Dawson, S. (1992). A consumer values orientation for materialism and its measurement: Scale development and validation. Journal of Consumer Research, 19, 303-316.

Richins, M. L. (2004).Properties and Development of the Material Value Scale. Journal of Consumer Reaserch, Vol. 31, No. 1: 209-219. 
Schmuck, Peter, Kasser, T. \& Ryan, M. R. (2000), "Intrinsic and Extrinsic Goals: Their Structure and Relationship to Well-Being in German and U.S. College Students," Social Indicators Research, 50 (2), 225-241.

Sirgy, J. M. (1998). Materialism and quality of life. Social Indicators Research, 43(3), 227260

Smith, Jennifer, M. (2010). A longitudinal and cross-sectional examination of the relationships between materialism and well-being and depressive symptoms. Counselling Psychology Dissertations.

Spielberger, C. D., Gorsuch, R. L., Lushene, R., Vagg, P. R., \& Jacobs, G. A. (1970). Manual for the State-Trait Anxiety Inventory. Palo Alto, CA: Consulting Psychologists Press.

Thacore, V.R, Gupta S.C., Suraiya M. Psychiatric morbidity in a north Indian community. Br J Psychiatry. 1975 Apr; 126:365-369. [PubMed]

Tyssen. R, . Factors in medical school that predict postgraduate mental health problems in need of treatment. A nationwide and longitudinal study. Medical Education 35:110120, 2008

Wachtel, P.L. \& Blatt, S.J. (1990). Perceptions of Economic Needs and of Anticipated Future Incomes. Journal of Economic Psychology, 11, 403-415.

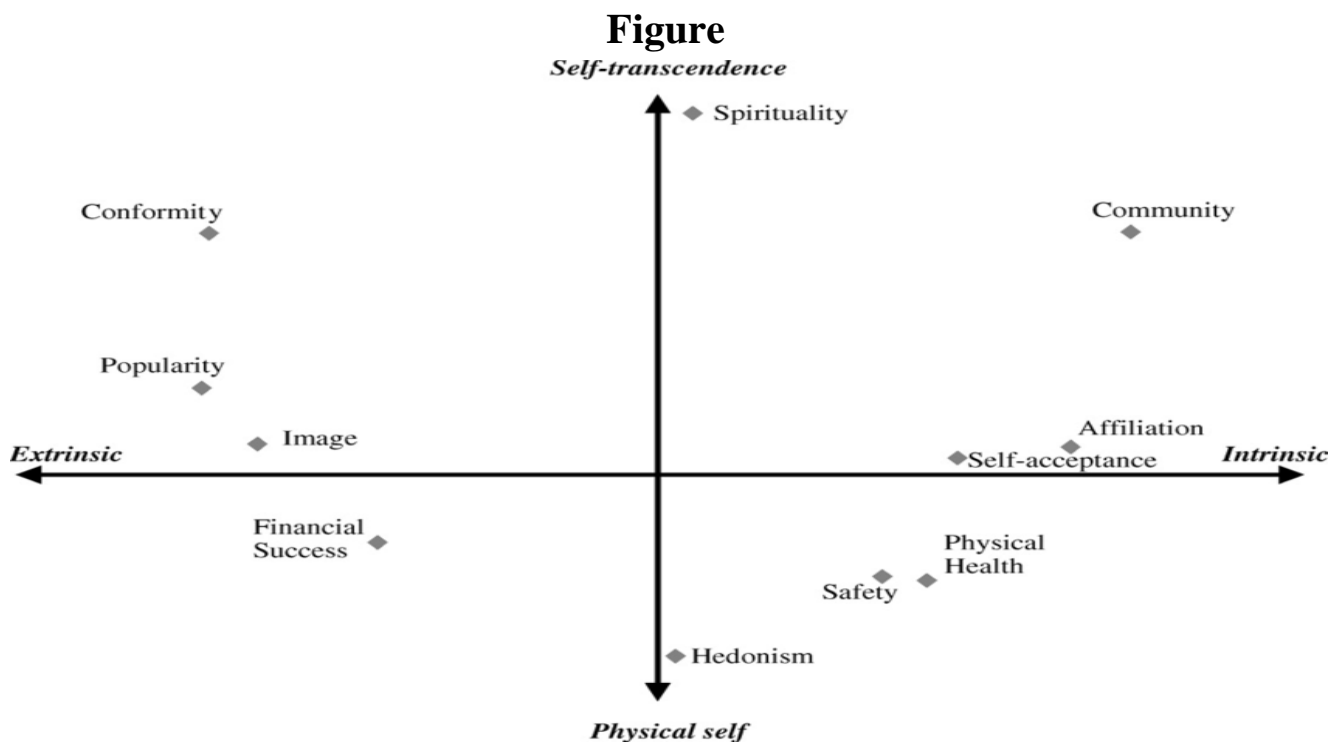

Fig.1 Circumplex model of aspiration goal

\section{Tables}

Descriptive statistics for the different groups of subjects in each of the types of psychiatric morbidity are presented in the following tables: 
Table-1: Means(M) and standard deviations(SD) of the measures of different types of psychiatric morbidity for undergraduate(UG) and postgraduate(PG) participants irrespective of sex:

\begin{tabular}{cccccc}
\hline Grade & & $\begin{array}{c}\text { State } \\
\text { Anxiety }\end{array}$ & $\begin{array}{c}\text { Trait } \\
\text { Anxiety }\end{array}$ & Depression & $\begin{array}{c}\text { Global } \\
\text { Psychiatric } \\
\text { Morbidity }\end{array}$ \\
\hline UG & M & 41.80 & 43.79 & 13.45 & 7.28 \\
& SD & 8.04 & 7.82 & 9.23 & 5.38 \\
& M & 40.53 & 43.54 & 11.02 & 5.49 \\
& SD & 9.26 & 8.42 & 8.43 & 4.87 \\
\hline
\end{tabular}

Table-2: Means(M) and standard deviations(SD) of the measures of different types of psychiatric morbidity for male and female participants irrespective of grade

\begin{tabular}{cccccc}
\hline \multirow{2}{*}{ Sex } & & $\begin{array}{c}\text { State } \\
\text { Anxiety }\end{array}$ & $\begin{array}{c}\text { Trait } \\
\text { Anxiety }\end{array}$ & Depression & $\begin{array}{c}\text { Global } \\
\text { Psychiatric } \\
\text { Morbidity }\end{array}$ \\
\hline \multirow{2}{*}{ Male } & M & 41.09 & 43.21 & 12.28 & 6.35 \\
& SD & 9.16 & 7.58 & 9.41 & 5.28 \\
& M & 41.24 & 44.17 & 12.19 & 6.42 \\
& SD & 8.16 & 8.67 & 8.35 & 5.12 \\
\hline
\end{tabular}

The means and standard deviations of different variables in each of the types of psychiatric morbidity are given in the following tables:

Table3: Means(M) and standard deviations(SD) of the measures of different types of psychiatric morbidity for participants with high and low materialistic value irrespective of grade and sex.

\begin{tabular}{|c|c|c|c|c|c|}
\hline $\begin{array}{c}\text { Materialistic } \\
\text { Value }\end{array}$ & & $\begin{array}{c}\text { State } \\
\text { Anxiety }\end{array}$ & $\begin{array}{c}\text { Trait } \\
\text { Anxiety }\end{array}$ & Depression & $\begin{array}{c}\text { Global } \\
\text { Psychiatric } \\
\text { Morbidity }\end{array}$ \\
\hline \multirow[b]{2}{*}{ High } & $\mathrm{M}$ & 43.32 & 45.74 & 14.37 & 7.62 \\
\hline & SD & 8.37 & 6.78 & 8.05 & 4.83 \\
\hline \multirow[b]{2}{*}{ Low } & M & 39.10 & 41.68 & 10.19 & 5.20 \\
\hline & SD & 8.50 & 8.79 & 9.23 & 5.27 \\
\hline
\end{tabular}

(C) The International Journal of Indian Psychology, ISSN 2348-5396 (e)| ISSN: 2349-3429 (p) | 126 
Table-4: Means(M) and standard deviations(SD) of the measures of different types of psychiatric morbidity for participants with high and low intrinsic aspiration irrespective of grade and sex

\begin{tabular}{cccccc}
\hline $\begin{array}{c}\text { Intrinsic } \\
\text { Aspiration }\end{array}$ & $\begin{array}{c}\text { State } \\
\text { Anxiety }\end{array}$ & $\begin{array}{c}\text { Trait } \\
\text { Anxiety }\end{array}$ & Depression & $\begin{array}{c}\text { Global } \\
\text { Psychiatric } \\
\text { Morbidity }\end{array}$ \\
\hline High & M & 40.46 & 42.47 & 11.60 & 5.80 \\
& SD & 9.08 & 8.43 & 8.96 & 4.78 \\
Low & M & 41.90 & 44.91 & 12.90 & 6.99 \\
& SD & 8.21 & 7.61 & 9.11 & 5.55 \\
\hline
\end{tabular}

Table-5: Means(M) and standard deviations(SD) of the measures of different types of psychiatric morbidity for participants with high and low extrinsic aspiration irrespective of grade and sex

\begin{tabular}{cccccc}
\hline $\begin{array}{c}\text { Extrinsic } \\
\text { Aspiration }\end{array}$ & State & $\begin{array}{c}\text { Trait } \\
\text { Anxiety }\end{array}$ & $\begin{array}{c}\text { Global } \\
\text { Anxiety }\end{array}$ & Depression & $\begin{array}{c}\text { Psychiatric } \\
\text { Morbidity }\end{array}$ \\
\hline High & SD & 41.82 & 44.63 & 13.16 & 7.23 \\
& M & 8.90 & 7.99 & 9.61 & 5.70 \\
Low & SD & 80.48 & 42.66 & 11.28 & 5.51 \\
& & 8.43 & 8.15 & 8.04 & 4.47 \\
\hline
\end{tabular}

Table-6: Means(M) and standard deviations(SD) of the measures of different types of psychiatric morbidity for participants with high and low hedonistic aspiration irrespective of grade and sex

\begin{tabular}{cccccc}
\hline $\begin{array}{c}\text { Hedonistic } \\
\text { Aspiration }\end{array}$ & $\begin{array}{c}\text { Psychiatric } \\
\text { Morbidity } \\
\text { Type } \\
\text { Stat }\end{array}$ & $\begin{array}{c}\text { State } \\
\text { Anxiety }\end{array}$ & $\begin{array}{c}\text { Trait } \\
\text { Anxiety }\end{array}$ & Depression & $\begin{array}{c}\text { Global } \\
\text { Psychiatric } \\
\text { Morbidity }\end{array}$ \\
\hline High & M & 40.49 & 42.96 & 10.74 & 5.69 \\
Low & SD & 8.67 & 8.25 & 7.95 & 4.75 \\
& M & 41.85 & 44.38 & 13.76 & 7.09 \\
\hline
\end{tabular}


Table-7: Means(M) and standard deviations(SD) of the measures of different types of psychiatric morbidity for participants with high and low spiritual aspiration irrespective of grade and sex

\begin{tabular}{cccccc}
\hline $\begin{array}{c}\text { Spiritual } \\
\text { Aspiration }\end{array}$ & $\begin{array}{c}\text { Psychiatric } \\
\text { Morbidity } \\
\text { Type } \\
\text { Stat }\end{array}$ & $\begin{array}{c}\text { State } \\
\text { Anxiety }\end{array}$ & $\begin{array}{c}\text { Trait } \\
\text { Anxiety }\end{array}$ & Depression & $\begin{array}{c}\text { Global } \\
\text { Psychiatric } \\
\text { Morbidity }\end{array}$ \\
\hline High & M & 40.67 & 43.77 & 12.61 & 6.38 \\
Low & SD & 8.28 & 7.18 & 9.62 & 5.26 \\
& M & 41.67 & 43.56 & 11.84 & 6.39 \\
\hline
\end{tabular}

The results obtained from the three factor analysis of variance are presented in the following tables: [Mean Square=MS; F= F-ratio]

Table-8: Results of three factor analysis of variance with Grade, Sex and Materialistic Value (MV) for measures of State Anxiety (SA), Trait Anxiety, Depression (Dep) and Global Psychiatric Morbidity (GPM)

\begin{tabular}{|c|c|c|c|c|c|c|c|c|}
\hline \multirow{2}{*}{$\begin{array}{l}\text { Source } \\
\text { of } \\
\text { Variation }\end{array}$} & \multicolumn{2}{|c|}{ SA } & \multicolumn{2}{|c|}{ TA } & \multicolumn{2}{|c|}{ Dep } & \multicolumn{2}{|c|}{ GPM } \\
\hline & MS & $\mathbf{F}$ & MS & $\mathbf{F}$ & MS & $\mathbf{F}$ & MS & $\mathbf{F}$ \\
\hline Grade & 112.750 & 1.586 & 8.238 & 0.130 & 339.568 & $4.575^{*}$ & 169.772 & 6.835* \\
\hline Sex & 1.397 & 0.020 & 41.112 & 0.650 & 0.099 & 0.001 & 0.496 & 0.020 \\
\hline MV & 874.356 & $12.298 * *$ & 788.856 & $12.480 * *$ & 847.662 & $11.422 * *$ & 284.864 & $11.468 * *$ \\
\hline $\begin{array}{l}\text { Grade X } \\
\text { Sex }\end{array}$ & 264.710 & 3.723 & 0.595 & 0.009 & 45.361 & 0.611 & 17.903 & 0.721 \\
\hline Sex X MV & 5.639 & 0.079 & 16.733 & 0.265 & 32.414 & 0.437 & 28.493 & 1.145 \\
\hline $\begin{array}{l}\text { Grade X } \\
\text { MV }\end{array}$ & 59.494 & 0.837 & 16.935 & 0.268 & 162.758 & 2.193 & 51.099 & 2.057 \\
\hline $\begin{array}{l}\text { Grade X } \\
\text { Sex X MV }\end{array}$ & 4.989 & 0.070 & 40.281 & 0.637 & 63.194 & 0.851 & 26.954 & 1.085 \\
\hline
\end{tabular}


Table-9: Results of three factor analysis of variance with Grade, Sex and Intrinsic Aspiration (IA) for measures of State Anxiety (SA), Trait Anxiety, Depression (Dep) and Global Psychiatric Morbidity (GPM)

\begin{tabular}{|c|c|c|c|c|c|c|c|c|}
\hline \multirow{2}{*}{$\begin{array}{l}\text { Source } \\
\text { of } \\
\text { Variation }\end{array}$} & \multicolumn{2}{|c|}{ SA } & \multicolumn{2}{|c|}{ TA } & \multicolumn{2}{|c|}{ Dep } & \multicolumn{2}{|c|}{ GPM } \\
\hline & MS & $\mathbf{F}$ & MS & $\mathbf{F}$ & MS & $\mathbf{F}$ & MS & $\mathbf{F}$ \\
\hline Grade & 96.495 & 1.278 & 4.385 & 0.066 & 305.489 & 3.828 & 1570.68 & 5.999* \\
\hline Sex & 2.772 & 0.037 & 49.206 & 0.744 & 0.122 & 0.002 & 1.057 & 0.040 \\
\hline IA & 94.987 & 1.285 & 285.602 & $4.317 *$ & 78.734 & 0.987 & 60.539 & 2.312 \\
\hline $\begin{array}{l}\text { Grade X } \\
\text { Sex }\end{array}$ & 271.707 & 3.599 & 0.947 & 0.014 & 51.722 & 0.648 & 15.968 & 0.610 \\
\hline Sex X IA & 0.559 & 0.007 & 14.771 & 0.223 & 5.666 & 0.071 & 44.260 & 1.691 \\
\hline $\begin{array}{l}\text { Grade X } \\
\text { IA }\end{array}$ & 0.016 & 0.000 & 13.606 & 0.206 & 2.950 & 0.037 & 6.783 & 0.259 \\
\hline $\begin{array}{l}\text { Grade X } \\
\text { Sex X IA }\end{array}$ & 19.484 & 0.258 & 10.747 & 0.162 & 5.077 & 0.064 & 34.883 & 1.332 \\
\hline
\end{tabular}

Table-10: Results of three factor analysis of variance with Grade, Sex and Extrinsic Aspiration (EA) for measures of State Anxiety (SA), Trait Anxiety, Depression (Dep) and Global Psychiatric Morbidity (GPM)

\begin{tabular}{|c|c|c|c|c|c|c|c|c|}
\hline \multirow{2}{*}{$\begin{array}{l}\text { Source } \\
\text { of } \\
\text { Variation }\end{array}$} & \multicolumn{2}{|c|}{ SA } & \multicolumn{2}{|c|}{ TA } & \multicolumn{2}{|c|}{ Dep } & \multicolumn{2}{|c|}{ GPM } \\
\hline & MS & $\mathbf{F}$ & MS & $\mathbf{F}$ & MS & $\mathbf{F}$ & MS & $\mathbf{F}$ \\
\hline Grade & 103.879 & 1.391 & 6.273 & 0.095 & 316.204 & 4.069* & 158.338 & 6.064 \\
\hline Sex & 1.590 & 0.021 & 42.518 & 0.646 & 0.043 & 0.001 & 0.902 & 0.035 \\
\hline EA & 90.851 & 1.216 & 184.866 & 2.810 & 158.760 & 2.043 & 142.724 & 5.466 \\
\hline $\begin{array}{l}\text { Grade X } \\
\text { Sex }\end{array}$ & 289.216 & 3.872 & 2.737 & 0.042 & 59.519 & 0.766 & 13.369 & 0.512 \\
\hline Sex X EA & 34.473 & 0.515 & 42.108 & 0.640 & 92.872 & 1.195 & 1.871 & 0.072 \\
\hline $\begin{array}{l}\text { Grade X } \\
\text { EA }\end{array}$ & 83.191 & 1.114 & 66.730 & 1.014 & 222.370 & 2.862 & 26.784 & 1.026 \\
\hline $\begin{array}{l}\text { Grade X } \\
\text { Sex X EA }\end{array}$ & 62.998 & 0.258 & 0.843 & 1.670 & 24.959 & 0.321 & 0.520 & 0.020 \\
\hline
\end{tabular}


Table-11: Results of three factor analysis of variance with Grade, Sex and Hedonistic Aspiration (HA) for measures of State Anxiety (SA), Trait Anxiety, Depression (Dep) and Global Psychiatric Morbidity (GPM)

\begin{tabular}{|c|c|c|c|c|c|c|c|c|}
\hline \multirow{2}{*}{$\begin{array}{l}\text { Source } \\
\text { of } \\
\text { Variation }\end{array}$} & \multicolumn{2}{|c|}{ SA } & \multicolumn{2}{|c|}{ TA } & \multicolumn{2}{|c|}{ Dep } & \multicolumn{2}{|c|}{ GPM } \\
\hline & MS & $\mathbf{F}$ & MS & $\mathbf{F}$ & MS & $\mathbf{F}$ & MS & $\mathbf{F}$ \\
\hline Grade & 105.047 & 1.420 & 5.648 & 0.084 & 331.770 & 4.306* & 167.756 & $6.437 *$ \\
\hline Sex & 2.699 & 0.036 & 47.082 & 0.703 & 0.409 & 0.005 & 2.007 & 0.077 \\
\hline HA & 86.061 & 1.163 & 94.616 & 1.413 & 454.807 & $5.902 *$ & 106.786 & 4.098* \\
\hline $\begin{array}{l}\text { Grade X } \\
\text { Sex }\end{array}$ & 275.783 & 3.728 & 1.276 & 0.019 & 52.922 & 0.687 & 13.283 & 0.510 \\
\hline Sex X HA & 121.983 & 1.649 & 21.054 & 0.314 & 71.428 & 0.927 & 2.309 & 0.089 \\
\hline $\begin{array}{l}\text { Grade X } \\
\text { HA }\end{array}$ & 175.497 & 2.372 & 14.769 & 0.221 & 62.814 & 0.815 & 68.127 & 2.614 \\
\hline $\begin{array}{l}\text { Grade X } \\
\text { Sex X HA }\end{array}$ & 1.445 & 0.020 & 33.082 & 0.494 & 1.569 & 0.020 & 7.926 & 0.304 \\
\hline
\end{tabular}

Table-12: Results of three factor analysis of variance with Grade, Sex and Spiritual Aspiration (SpA) for measures of State Anxiety (SA), Trait Anxiety, Depression (Dep) and Global Psychiatric Morbidity (GPM)

\begin{tabular}{|c|c|c|c|c|c|c|c|c|}
\hline \multirow{2}{*}{$\begin{array}{l}\text { Source } \\
\text { of } \\
\text { Variation }\end{array}$} & \multicolumn{2}{|c|}{ SA } & \multicolumn{2}{|c|}{ TA } & \multicolumn{2}{|c|}{ Dep } & \multicolumn{2}{|c|}{ GPM } \\
\hline & MS & $\mathbf{F}$ & MS & $\mathbf{F}$ & MS & $\mathbf{F}$ & MS & $\mathbf{F}$ \\
\hline Grade & 94.180 & 1.264 & 3.769 & 0.056 & 296.025 & 3.727 & 151.572 & $5.678^{*}$ \\
\hline Sex & 2.745 & 0.037 & 51.758 & 0.772 & 0.137 & 0.002 & 1.523 & 0.057 \\
\hline SpA & 50.501 & 0.678 & 1.089 & 0.016 & 40.494 & 0.510 & 0.043 & 0.002 \\
\hline $\begin{array}{l}\text { Grade X } \\
\text { Sex }\end{array}$ & 280.378 & 3.762 & 2.415 & 0.036 & 55.066 & 0.693 & 13.698 & 0.513 \\
\hline Sex X SpA & 18.367 & 0.246 & 111.502 & 1.662 & 11.422 & 0.144 & 1.726 & 0.065 \\
\hline $\begin{array}{l}\text { Grade X } \\
\text { SpA }\end{array}$ & 225.957 & 3.032 & 22.183 & 0.331 & 118.283 & 1.489 & 50.649 & 1.898 \\
\hline $\begin{array}{l}\text { Grade X } \\
\text { Sex X SpA }\end{array}$ & 10.162 & 0.136 & 14.372 & 0.214 & 0.323 & 0.004 & 6.671 & 0.250 \\
\hline
\end{tabular}

How to cite this article: Biswas A \& Das S (2017). Materialism and Its Effect on Psychiatric Morbidity of Indian Students. International Journal of Indian Psychology, Vol. 5, (1), DIP: 18.01.113/20170501, DOI: 10.25215/0501.113 